Gut, 1980, 21, 23-25

\title{
Outlook with conservative treatment of peptic oesophageal stricture
}

\author{
A L OGILVIE, R FERGUSON, AND M ATKINSON \\ From University Hospital, Nottingham
}

SUMMARY In order to assess the outlook for patients with peptic oesophageal strictures treated by Eder Puestow dilatation at fibreoptic endoscopy, 50 patients were followed up for periods ranging from nine months to four years. Twenty patients $(40 \%)$ required only a single dilatation, and the remaining $30(60 \%)$ required multiple dilatations. The frequency of dilatation tended to decrease with time. There was one death attributable to the procedure. Two patients developed an adenocarcinoma at the site of the stricture. We conclude that conservative management of peptic oesophageal stricture combining the use of dilatation at fibreoptic endoscopy with medical measures to control gastro-oesophageal reflux offers a relatively safe means of providing symptomatic relief, maintaining nutrition, and allowing the patient an acceptable quality of life.

As patients with peptic oesophageal strictures are often elderly and debilitated, they are usually managed conservatively by peroral dilatation of the stricture combined with measures to combat gastrooesophageal reflux. The use of fibreoptic endoscopes and the Eder Puestow dilators has made dilatation simpler and safer, ${ }^{1-3}$ but the long-term outlook for patients so treated is still uncertain.

To determine the need for repeated dilatation and the risk that this entails, we have made a prospective study of 54 consecutive patients with peptic stricture managed conservatively.

\section{Methods}

\section{PATIENTS}

Fifty-four patients, 23 men and 31 women, each presenting with dysphagia, underwent an initial dilatation for peptic stricture in the four year period 1975-78. Their ages ranged from 47 to 90 years with a mean of 69 years, and $69 \%$ were over 65 years.

All had gastro-oesophageal reflux with endoscopic evidence of oesophagitis. A stricture followed cardiomyotomy for achalasia in two patients, resection of a high lesser curve gastric ulcer in one patient, and prolonged nasogastric intubation after cholecystectomy in one patient. In addition, one suffered from the Zollinger-Ellison syndrome for which he had previously undergone total gastrectomy and in another gastro-oesophageal reflux complicated systemic sclerosis. Three patients had previously undergone a fundoplication operation

Received for publication 10 August 1979 to control gastro-oesophageal reflux and had subsequently developed a peptic oesophageal stricture. At the time of initial dilatation the lumen of the stricture was $10 \mathrm{~mm}$ or less in all. The stricture was in the lower oesophagus in 39 and in the middle third of the oesophagus in 15, three of whom had columnar epithelium lining the oesophagus (Barrett's oesophagus).

\section{PROCEDURES}

Strictures were dilated by the Eder Puestow method: a Puestow stainless steel guidewire, inserted down the biopsy channel of the Olympus GIFK or GIF P2 endoscope, was passed through the stricture under direct vision. Occasionally, difficulty was encountered in passing the wire onward into the stomach and here $x$-ray screening using a mobile image intensifier was used to check whether pressure against the wall of the oesophagus or stomach was causing the tip of the wire to be bent back. If so, the wire was withdrawn until its tip straightened out and then, by angulation of the endoscope, its direction of passage was altered slightly until it passed easily into the stomach. Thereafter the endoscope was removed, leaving the guidewire in position, and the stricture was dilated by sliding metal olives of progressively increasing size along the wire starting with a 23 French gauge olive (diameter $7.3 \mathrm{~mm}$ ) and working up to a number 45 French gauge olive (diameter $14.3 \mathrm{~mm}$ ). At each dilatation biopsies and cytology brushings were taken. Strictures were dilated initially under general anaesthesia but subsequently local anaesthesia was often used. 
Patients were kept in hospital for 24 hours after dilatation and allowed to eat after eight hours.

After initial dilatation, measures were taken to combat gastro-oesophageal reflux. These comprised sleeping with the head of the bed raised on $10 \cdot 2$ $\mathrm{cm}$ (4 in) blocks, administration of an antacid containing dimethicone and of metoclopramide 10 mg q.d.s. together with advice where necessary to counter obesity and smoking. Attention was given to the provision of properly fitted dentures where necessary. All patients were reviewed regularly in the Outpatient Clinic and endoscopy was repeated if dysphagia recurred. Dilatation was repeated if the GIFK endoscope (diameter $12.5 \mathrm{~mm}$ ) would not pass through the stricture.

\section{Results}

One hundred and eighty-eight dilatations were performed in 54 patients over the four year period. The one fatality in the series occurred in an 87 year old woman who sustained a perforation at the time of the initial dilatation. Two other patients died shortly after the initial dilatation from unrelated causes. In a fourth patient with the ZollingerEllison syndrome a further dilatation proved impossible and this represents the only technical failure.

Fifty patients have been followed up for periods ranging from nine months to four years. During follow-up 12 have died, all from causes unrelated to the oesophageal lesion. Adenocarcinoma developed at the site of a long-standing fibrous stricture in two other patients, both of whom had columnar epithelium lining the lower oesophagus. Both had suffered from dysphagia for $2 \frac{1}{2}$ years before the diagnosis of carcinoma was made and examination of the resected stricture in one patient and the necropsy specimen in the other showed that the growths arose in a fibrous stricture.

Twenty patients have not required a second dilatation during follow-up periods ranging up to four years, and the remaining 30 patients have been dilated up to a maximum of 18 dilatations in one patient over the four year period. There was no difference in the age, length of follow-up, sex, site, and length or diameter of stricture between those patients who needed additional dilatation and those who did not.

The number of dilatations required in the first, second, and third years after the initial dilatation is shown in Table 1 . The number of dilatations required fell during each year of follow-up from an average of 1.7 dilatations per person in the first year to 0.6 during the third year of follow-up. The possibility that this apparent improvement in outlook with time was due to the early deaths of those
Table 1 Total number of dilatations during three years of follow-up

\begin{tabular}{llll}
\hline \multirow{2}{*}{$\begin{array}{l}\text { Additional } \\
\text { dilatations (no.) }\end{array}$} & \multicolumn{3}{l}{ Number of patients } \\
\cline { 2 - 4 } & 1st year & 2nd year & 3rd year \\
\hline 0 & 18 & 11 & 7 \\
$1-2$ & 9 & 7 & 1 \\
$3-4$ & 11 & 3 & 1 \\
$>4$ & 3 & 1 & 0 \\
Total number of patients & 41 & 22 & 9 \\
Average no. of dilatations & 1.7 & 1.3 & $0.6^{*}$ \\
per patient & 1.7 & & \\
\hline
\end{tabular}

*Differs significantly from number of dilatations in first year $(P<0.05)$

Table 2 Additional dilatations during the first and second year of treatment in 22 patients.

\begin{tabular}{lll}
\hline \multirow{2}{*}{$\begin{array}{l}\text { Additional } \\
\text { dilatations (no.) }\end{array}$} & \multicolumn{2}{c}{ Number of patients } \\
\cline { 2 - 3 } & 1st year & 2nd year \\
\hline 0 & 8 & 11 \\
$1-2$ & 5 & 7 \\
$3-4$ & 7 & 3 \\
$>4$ & 2 & 1 \\
Total number of patients & 22 & 22 \\
Total number of & 43 & 28 \\
dilatations & & \\
\hline
\end{tabular}

Table 3 Additional dilatations during the first, second, and third year of treatment in nine patients.

\begin{tabular}{lccl}
\hline \multirow{2}{*}{$\begin{array}{l}\text { Additional } \\
\text { dilatations (no.) }\end{array}$} & \multicolumn{2}{c}{ Number of patients } \\
\cline { 2 - 4 } & 1st year & 2nd year & 3rd year \\
\hline 0 & 3 & 5 & 7 \\
$1-2$ & 2 & 1 & 1 \\
$3-4$ & 4 & 2 & 1 \\
$>4$ & 0 & 1 & 0 \\
Total number of patients & 9 & 9 & 9 \\
Total dilatations & 16 & 14 & 5 \\
\hline
\end{tabular}

patients with the most severe stricture seems unlike$1 y$, as the 22 patients who were followed up for more than two years needed fewer dilatations in the second year than in the first year (Table 2). A similar trend was seen in the group of nine patients who had completed three years' follow-up, fewer dilatations being required as time went on (Table 3 ).

Even when repeated dilatation of the stricture was necessary, nutritional status was maintained in all except two patients, one of whom suffered from progressive systemic sclerosis with intestinal involvement and the other required endoscopic insertion of a Celestin tube to maintain adequate nutrition. Although many patients avoided certain lumpy foods such as steak and raw apple their"diets were adequate, varied, and satisfying.

\section{Discussion}

Conservative management of peptic oesophageal stricture combining the use of the Eder Puestow dilators at fibreoptic endoscopy with medical measures to control reflux offers a relatively safe 
means of providing symptomatic relief, maintaining nutrition, and allowing the patient a satisfactory quality of life. The procedure offers an acceptably low mortality rate in a predominantly elderly population and compares well with rigid instrumentation and surgery. Our findings suggest that, with active medical measures to combat reflux, there is an overall decline in the need for dilatation with the passage of time and during the second year of follow-up only $50 \%$ of our patients needed a further dilatation. We were not able to predict at first dilatation those patients who would require multiple dilatations.

Disability caused by a peptic stricture is dependent not only upon the degree of luminal narrowing but also upon the patient's ability to masticate properly and upon the presence of active coordinated peristalsis in the oesophagus above the stricture. Peristalsis is often impaired or absent in the elderly and also in achalasia and systemic sclerosis. Adequate dilatation is essential to provide symptomatic relief in these patients, who may present a difficult problem of management even when the stricture is not tight.

The presence of columnar epithelium lining the oesophagus increases the risk of adenocarcinomatous change ${ }^{4}$ and this could account for the two adenocarcinomas in our series. However, in both our patients the growth arose in close proximity to a proven fibrous stricture, thus raising the possibility that chronic irritation may have predisposed to neoplastic change. Oesophageal carcinoma is recognised to be a long-term complication of oesophageal stricture after the ingestion of corrosive poison ${ }^{5}$ and, in 1977, Moghissi, ${ }^{6}$ reviewing 207 patients with carcinoma of the cardia, found that five $(2.4 \%)$ were associated with peptic oesophageal stricture suggesting that this may be of importance in the development of carcinoma.

\section{References}

${ }^{1}$ Lilly JO, McCaffery TD Jr. Esophageal stricture dilation: a new method adapted to the fibreoptic esophagoscope. Am J Dig Dis 1971; 16:1137-40.

${ }^{2}$ Royston CMS, Dowling BL, Gear MWL. Esophageal dilation using the Eder Puestow dilators. Am J Surg 1976;131:697-700.

${ }^{3}$ Bennett JR. Oesophageal strictures. Clin Gastroenterol 1978;7:555-69.

${ }^{4}$ McDonald GB, Brand DL, Thorning DR. Multiple adenomatous neoplasms arising in columnar-lined (Barrett's) esophagus. Gastroenterology 1977;72:131721.

${ }^{5}$ Kiviranta UK. Corrosion carcinoma of the esophagus; 381 cases of corrosion and 9 cases of corrosion carcinoma. Acta Otolaryngol (Stockh) 1952;42:89-95.

${ }^{6}$ Moghissi K. Carcinoma of the cardia and thoracic oesophagus coexisting with and following sliding hiatal hernia and peptic stricture. Thorax 1977;32:3425. 